\title{
Predicting the Total number of COVID-19 Deaths by County for the State of Florida: Ridge Regression Approach
}

\author{
B. M. GOLAM KIBRIA, MANUEL URBISTONDO \\ Department of Mathematics and Statistics \\ Florida International University \\ Miami, FL 33199, USA
}

\begin{abstract}
Coronavirus disease 2019 (COVID-19) is a novel infectious disease that was detected in Wuhan, China at the end of 2019. The virus quickly spread worldwide and caused a global pandemic. This paper investigates if there are any regressors that could help impact the number of deaths due to COVID-19. The variables that were used in the models were total deaths, hospitalizations, total cases, population, minimum temperature, average temperature, maximum temperature, precipitation, mobility index, median age, adults age 65 or older, PM2.5 average, ozone average, and positive non-residents. After fitting six different regression models, we found that the most significant regressors were hospitalizations per county, total cases per county, population per county, median age per county, positive adults 65 or older per county, and positive non-residents per county. The COVID-19 data of this paper will be an excellent source for illustrating the multicollinear linear regression models.
\end{abstract}

Key-Words: - Cross Validation; Linear Regression Model; MAPE; Multicollinearity; OLS; Ridge Regression; RMSE.

Received: June 22, 2021. Revised: November 21, 2021. Accepted: December 13, 2021. Published: December 31, 2021.

\section{Introduction}

Coronavirus Disease 19 (COVID-19) is the disease caused by a new coronavirus called SARS-CoV-2. It first appeared at the end of 2019 in Wuhan, China. It rapidly spread out throughout Asia and eventually in the world, leading the World Health Organization to declare a Public Health Emergency of International Concern and a global pandemic. The virus reached the West Coast of the United States in January 2020. On January $31^{\text {st }}$ President Donald Trump declared a public health emergency under the Public Health Service Act. These actions were taken to mitigate the potential impact in the United States. To date, coronavirus has infected about 66 million and killed about 872 thousand people in the United States. At present, in Florida, the total number of positive cases is above 5 million and about 63 thousand deaths (January 15, 2022).

The infectious disease COVID-19 may not have a high death ratio, but the potential long-term risks are still being studied. The most common symptoms of the disease are fever, cough, shortness of breath, fatigue, body aches, headache, loss of taste or smell, nausea, and other infrequent but possible ailments. Mild or moderate COVID-19 will last roughly two weeks for most people, but others suffer lingering health problems even when they have recovered from the illness. While it's clear that people with certain risk factors are more likely to have complications of COVID-19, there isn't a clear link between risk factors and long-term problems. This means COVID-19 can have prolonged effects, even on those who only suffered mild symptoms. The complete severity of coronavirus is still an unknown, for this reason, this disease is still the most prevalent topic in the world.

The purpose of this study is to fit different linear regression models and find possible variables that could contribute to the coronavirus death count in Florida. This paper will study all 67 counties in the state of Florida to determine if there are specific factors that could influence deaths due to COVID19. The data of this paper was collected in April 2021. The variables we used in the models are:

- Total Deaths (Y): Deaths due to coronavirus is our dependent variable. Each observation is tracked by deaths per county.

- Total Hospitalizations (X1): Hospitalizations could be related to more deaths due to severity of those that visited the hospital.

- Total Cases (X2): Coronavirus may have a high survival rate, but the amount of total 
cases could help predict the number of deaths.

- Population (X3): Considering how this disease is transmitted, areas with a higher population may influence the number of infected individuals in a particular area.

- Minimum Temperature (X4): We want to consider if areas with lower atmospheric temperature could have a relation to the infectious rate of the coronavirus.

- Average Temperature (X5): Average temperature could give us an idea of which counties have prevailing weather that could cause infection of the disease.

- Maximum Temperature (X6): COVID-19 is known to be less infectious in areas with warm weather. The maximum temperature could have a relation to areas that have less infections.

- Precipitation (X7): This is another environmental factors that we will consider that could influence COVID-19 deaths.

- Mobility Index (X8): Since COVID-19 is transmitted from person to person, counties with higher Mobility Index could have more deaths due to corona virus.

- Median Age (X9): COVID-19 affects ages differently. A higher median age could anticipate a larger number of deaths in a county.

- Age 65 or Older (X10): The death rate of the disease is increased dependent on the cases for people who are 65 or older.

- PM2.5 Average (X11): COVID-19 is a respiratory disease, higher levels of PM2.5 could affect the severity of the disease in a particular area.

- Ozone Average (X12): Areas where the ozone concentration is less could affect the spread of COVID-19.

- Positive Non-residents (X13): Areas where there are more positive non-residents could lead to a higher number of deaths due to COVID-19.

For detailed on linear regression models with applications, we refer to Draper and Smith (1998) and Montgomery (2013), and Abdullah et al. (2016) and recently Saleh et al. (2019) among others. There are limited number of applications in literature for fitting regression mode with COVID-19 data. First, Ghosal et al. (2020) consider SARS-CoV-2 at 6 weeks from day 0 data to predict the number of deaths in India. Qin et al. (2020) consider COVID-
19 data to predict the number of cases using social media search index data. Ogundokun et al. (2020) consider the regression model to predict the COVID-19 confirmed cases in Nigeria. However, none of the aforementioned researchers have addressed the issue of multicollinearity, ie, when the regressors in the linear regression model are correlated. There were many papers those handle the problem of multicollinearity. To mention a few, Gibon (1978), Kibria (2003), Gruber (2010), Muniz and Kibria (2009), Muniz et al (2012), Kibria and Banik (2016), Lukman et al. (2019a, 2019b), Kibria and Lukman (2020), Suhail et al. (2020), and very recently Qasim et al. (2021) and Amin et al. (2021) among others.

The objective of this paper is two folds: (i) Find a suitable model that provides the better prediction of deaths (ii) The data of this paper will be an important source for illustrating multicollinear linear regression model. The organization of the paper is as follows: The sources of data and descriptive statistics are given in section 2. The statistical models and data analysis are given in section 3. Cross validation about the models are given in section 4. Finally, some concluding remarks are provided in section 5 .

\section{Data Collection and Descriptive Statistics}

\subsection{Data Collection}

The focus when collecting data was to see which factors can help predict COVID-19 deaths in each Florida county. The initial data collection was challenging due to the information being limited for some particular counties around the state. At the beginning of the project, the timeline of the data was going to only be from January 2020 until January 2021. We believed this would be the most accurate time for our variables to be significant. However, the statistics we collected are either the total until April 5, 2021 or it was recorded on a yearly basis. The most complete data set we were able to find was from Florida Department of Health, Division of Disease Control and Health Protection. Their Florida's COVID-19 Data and Surveillance Dashboard presents a variety of statistics for each Florida county. Their county cases map gives the information for total number of deaths, hospitalizations, population, positive residents, and positive non-residents. It also states the median age, and total number of people age 65 or older for each 
county. These variables were the totals until April 5, 2021.

We also wanted to consider if there were any environmental factors that could help us predict the number of deaths due to coronavirus. The National Oceanic and Atmospheric Administration (NOAA) provides a county map called Climate at a Glance. The map offers the statistics for minimum temperature, average temperature, maximum temperature, and precipitation for each county and at the time of your choosing. We recorded each of the previous variables for the 67 counties and selected the data to be dated from January 2020 to January 2021.

There were different environmental factors that we considered to use. Since COVID-19 is a respiratory disease, we wanted to find any air pollutants that could exaggerate the infection of coronavirus. The Florida Department of Environmental Protection reports data on the carbon Monoxide (CO), Nitrogen Dioxide (NO2), Ozone (O3), Particular Matter Trend (PM10), Particular Matter Pollution (PM2.5) and Sulfur Dioxide (SO2) averages for a number of Florida counties. However, only (PM2.5) and (O3) averages had data for at least 32 of the 67 counties. To complete the values for each of the 67 counties, we estimated the missing data by averaging the values from the neighboring counties. If there was any data value that was not given for the PM2.5 or Ozone average, it was estimated by averaging the value of the closest 2 counties. The PM2.5 and Ozone averages were recorded from the yearly 2020 report. The last data variable that was collected was for Mobility Index by county. It is the measure the daily average distance traveled. The Center for Disease Control and Prevention has a COVID Data Tracker that contributes the Mobility Index for each county. The data was collected as the average Mobility Index for the past year. The complete data set is presented in the Appendix of this paper.

\subsection{Descriptive Statistics}

The following Table 1 contains the descriptive statistics for each of the 14 variables that will be used for the multiple linear regression models in the following section. It provides the minimum, maximum, median, mean, and the standard deviation of the data set value for each variable (1 dependent variable and the 13 independent variables).

All analyses of this paper are done by free software $\mathrm{R}$ 4.1.1, which is available from online. However, one can use the books by Cohen and Cohen (2008, 2021) among others.

Table 1 . Summary statistics of the variables

\begin{tabular}{|l|l|l|l|l|l|l|}
\hline & Variables & Min & Max & Median & Mean & Standard Deviation \\
\hline Y & Deaths & 16 & 5900 & 259 & 502.3 & 871.061 \\
\hline X1 & Hospitalizations & 22 & 12624 & 610 & 1279 & 2124.816 \\
\hline X2 & Total Cases & 926 & 449891 & 8852 & 30947 & 64400.11 \\
\hline X3 & Population & 8354 & 2716940 & 132420 & 320563 & 501304.4 \\
\hline X4 & Min. Temperature & 57.5 & 70.4 & 62.9 & 62.57 & 3.4107 \\
\hline X5 & Avg. Temperature & 68.4 & 78.5 & 72.9 & 72.68 & 2.746 \\
\hline X6 & Max Temperature & 78.7 & 86.6 & 82.7 & 82.78 & 2.242 \\
\hline X7 & Precipitation & 47.47 & 78.94 & 54.82 & 57.61 & 7.331 \\
\hline X8 & Mobility Index & 3.8 & 4.4 & 4.1 & 4.131 & 0.169 \\
\hline X9 & Median Age & 27 & 65 & 43 & 42.82 & 5.447 \\
\hline X10 & Age 65 or More & 116 & 55621 & 2433 & 4593 & 7925.297 \\
\hline X11 & PM2.5 Average & 15.28 & 32.86 & 20.5 & 21.95 & 4.769 \\
\hline X12 & Ozone Average & 50.4 & 63 & 57.5 & 57.3 & 2.311 \\
\hline X13 & Positive Non-Residents & 0 & 5773 & 103 & 539.7 & 984.75 \\
\hline
\end{tabular}




\section{Statistical Analysis}

We will consider the following linear regression model:

$y=\beta_{0}+\beta_{1} x_{1}+\beta_{2} x_{2}+\beta_{3} x_{3}+\beta_{4} x_{4}+\beta_{5} x_{5}+\beta_{6} x_{6}+\beta_{7} x_{7}$

$+\beta_{8} \mathrm{X}_{8}+\beta_{9} \mathrm{X}_{9}+\beta_{10} \mathrm{X}_{10}+\beta_{11} \mathrm{X}_{11}+\beta_{12} \mathrm{X}_{12}+\beta_{13} \mathrm{X}_{13}+\varepsilon$

where $\mathrm{y}=$ total deaths because of COVID-19, $\mathrm{x} 1=$ hospitalizations per county, $\mathrm{x} 2=$ total cases per county, $\mathrm{x} 3=$ population per county, $\mathrm{x} 4=$ minimum temperature per county, $\mathrm{x} 5=$ average temperature per county, $\mathrm{x} 6=\max$ temperature per county, $\mathrm{x} 7=$ precipitation per county, $\mathrm{x} 8=$ mobility index per county, $x 9=$ median age per county, $x 10=$ age 65 or more per county, $\mathrm{x} 11=\mathrm{PM} 2.5$ average per county, $\mathrm{x} 12=$ ozone average per county, and $\mathrm{x} 13=$ positive non-residents per county. In order to fit the model, we will assume that all regressors are independent and that the residuals are normally distributed with mean 0 and variance $\sigma^{2}$. In this section we will fit different types of regression models and try to find a possible best model.

\subsection{Full Model (Model 1)}

Using $\mathrm{R}$ software, we obtain the following regression analysis for model 1 .

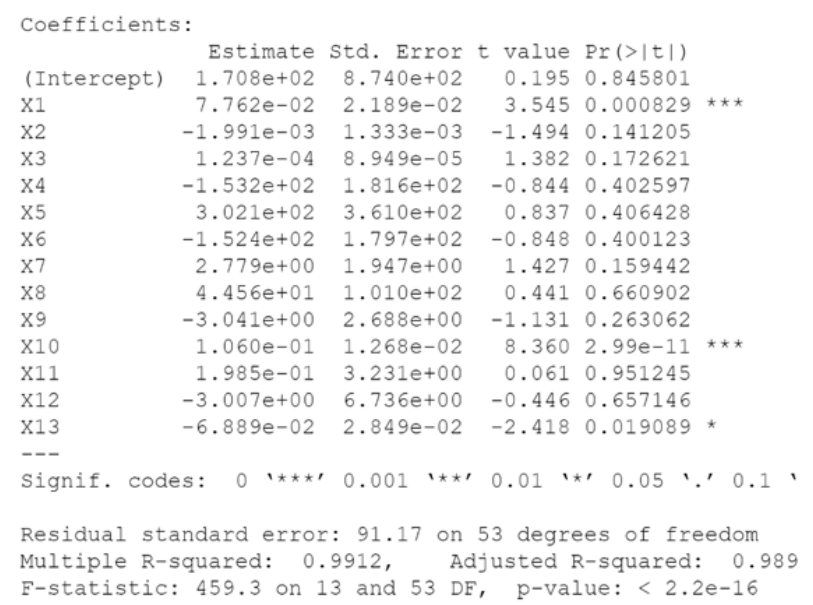

The first fitted model (model 1) is, $\hat{y}=0.01708+0.07762 \times 1-0.001991 \times 2+0.0001237 \times 3-$ $0.01532 \times 4+0.03021 \times 5-$

$0.01524 \times 6+2.779 \times 7+0.4456 \times 8-$

$3.041 \times 9+0.106 \times 10+0.1985 \times 11-3.007 \times 12-$ $0.06889 \times 13$

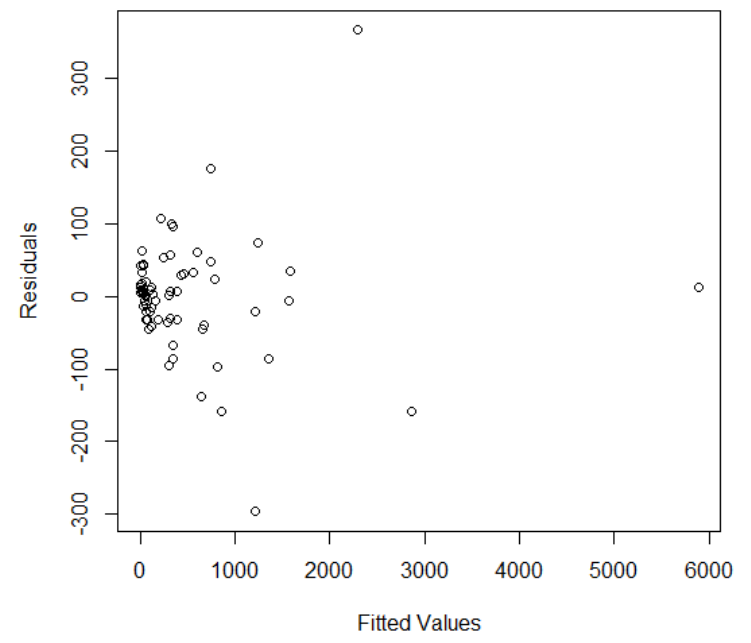

Fig. 1: Residual vs fitted plot for model 1

From (Model 1) we can see that the $\mathrm{R}$ Square is 0.9912 , which means that about $99 \%$ of total variation of deaths due to COVID-19 can be explained by the 13 variables. There are only three regressors statistical significant. However, the pvalue in (Model 1) is significantly less than 0.05 ; then, we can reject the null hypothesis that the regressors are not significant. Hence, we can assume that at least one of the 13 variables are significant to the model. To check the model diagnostics, the residuals vs. fitted plot and normal Q-Q plot are shown in Figures 1 and 2 respectively.

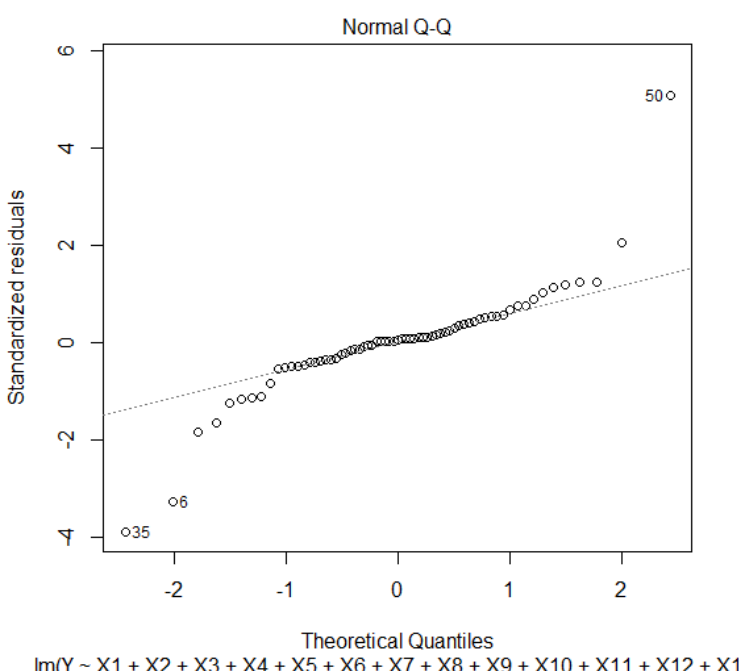

Fig. 2: Q-Q plot of the residuals for model 1

The Residuals vs Fitted plot (Figure 1) demonstrates how the data is clustered to the left, suggesting that the variance is not constant. Since the residuals 
seem to follow a heavy-tailed distribution within the Normal Q-Q plot (Figure 2), we cannot conclude that the distribution of these residuals is completely normal. Although the residuals at the extremities are not close to the line, the center of the graph may indicate that the distribution is approximately normal. A Shapiro Wilk test of normality (pvalue $=0.0000013$ ) will test the null hypothesis that the residuals are normally distributed. The $\mathrm{p}$-value is significantly less than 0.05 , we reject the null hypothesis and conclude the model is not normally distributed. Thus the full model is not adequate to predict the total number of deaths.

Since Model 1 is not an adequate to predict the number of deaths per county, we tried several different transformations on the dependent variable.

\subsection{Log Transformation Model (Model 2)}

First we attempted the most popular log (y) transformation model:

$$
\begin{aligned}
& \log (\hat{y})=\beta 0+\beta 1 \times 1+\beta 2 \times 2+\beta 3 \times 3+\beta 4 \times 4 \\
& +\beta 5 \times 5+\beta 6 \times 6+\beta 7 \times 7+\beta 8 \times 8+\beta 9 \times 9+\beta 10 \times 10 \\
& +\beta 11 \times 11+\beta 12 \times 12+\beta 13 \times 13+\varepsilon
\end{aligned}
$$

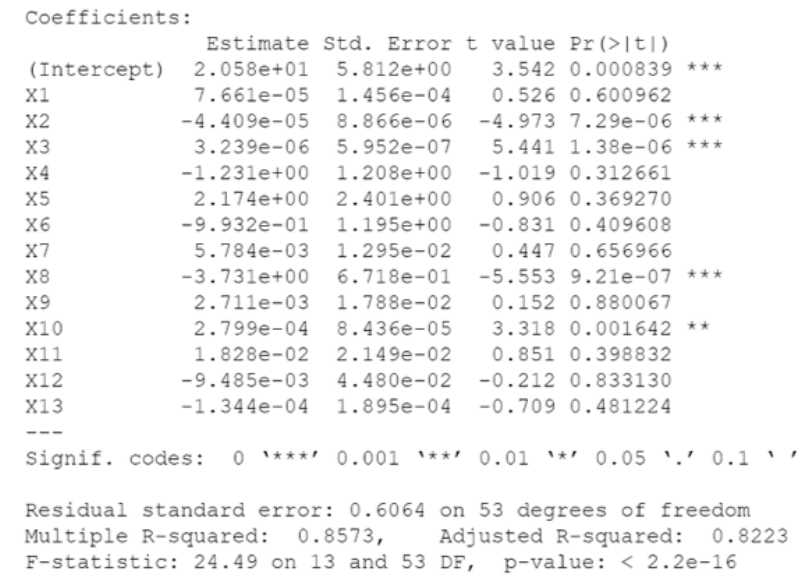

The fitted regression model (model 2 ) is

$\log (\hat{y})=20.58+0.00007661 \times 1-$

$0.00004409 \times 2+0.000003239 \times 3-1.231 \times 4+2.174 \times 5-$

$0.9932 \times 6+0.005784 \times 7-$

$3.731 \times 8+0.002711 \times 9+0.0002799 \times 10+0.01828 \times 11-$ $0.009485 \times 12-0.000134 \times 13$

Model 2 has $\mathrm{R}$ square equal to 0.8573 , which represents that almost $86 \%$ of total variation of deaths due to COVID-19 can be explained by the 13 variables. The $\mathrm{R}$ square for (Model 2) is less than the $\mathrm{R}$ square for (Model 1). The p-value in (Model 2 ) is still significantly less than 0.05 ; we reject the null hypothesis that the regressors are not significant. Hence, we can assume that at least one of the 13 variables are significant in (Model 2). To check the model diagnostics, residuals vs. fitted plot and the normal Q-Q plot are shown in Figures 3 and 4 respectively.

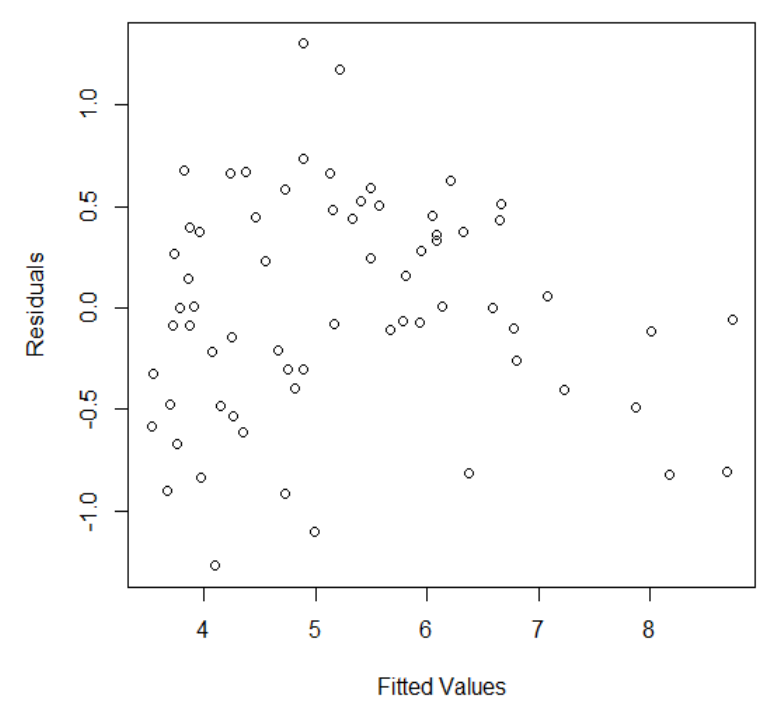

Fig. 3: Residual vs fitted plot for model 2

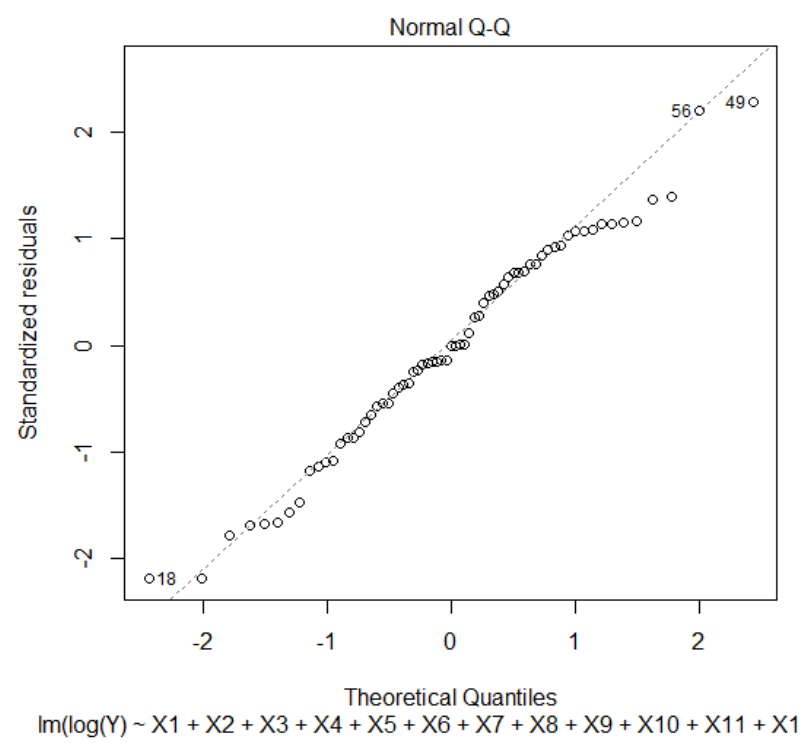

Fig. 4: Q-Q plot of the residuals for model 2

The log transformation significantly improved the residuals vs fitted plot and normal Q-Q plot. Figure 3 follows a more scattered pattern around 0 than that of Figure 1, yet the data is still slightly scattered to the left side of the graph. Figure 4 shows an improvement on the normal probability plot of the residuals. The normality line is straighter and more of the residuals lie on the line. The Shapiro-Wilk 
test on the residuals has a p-value $=0.5147$, we cannot reject the null hypothesis that the residuals are normally distributed. This model meets the normality of residuals assumption. We can carry on using the full log transformation.

\subsection{Reduced Log Transformation (Model 3)}

$\mathrm{y}=\beta_{0}+\beta_{2} \mathrm{X}_{2}+\beta_{3} \mathrm{X}_{3}+\beta_{4} \mathrm{X}_{4}+\beta_{8} \mathrm{X}_{8}+\beta_{10} \mathrm{X}_{10}+\varepsilon$

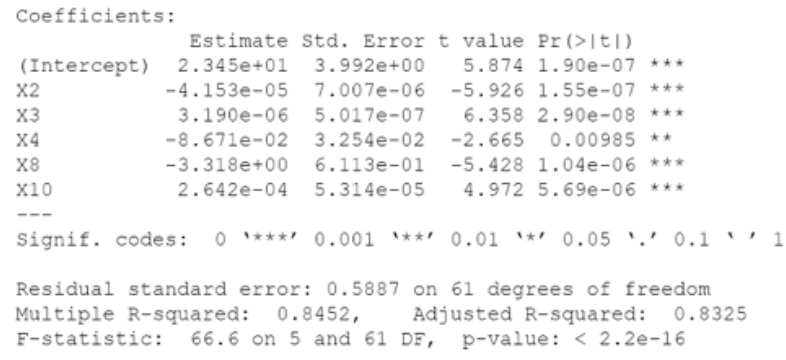

The fitted reduced model (model 3 ) is $\log (\hat{y})=23.45-0.00004153 \times 2+0.000003190 \times 3-$ $0.08671 \times 4-3.318 \times 8+0.0002642 \times 10$

The results show that $\mathrm{R}$ square is 0.8452 , which represents that almost $85 \%$ of total variation of deaths due to COVID-19 can be explained by these 5 variables. The $\mathrm{R}$ square for (Model 3 ) is slightly less than the $\mathrm{R}$ square for (Model 2). To check the model diagnostics, residuals vs. fitted plot and the normal Q-Q plot are shown in Figures 5 and 6 respectively.

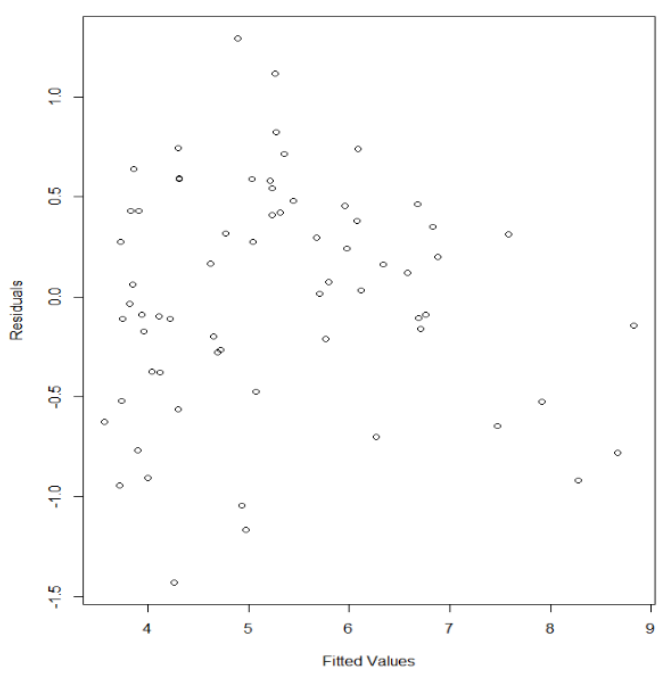

Fig. 5: Residual vs fitted plot for model 3

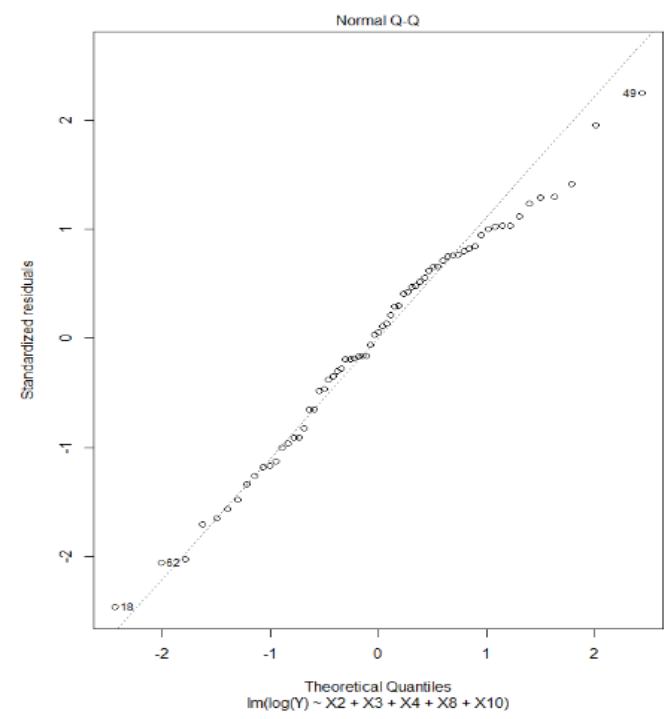

Fig. 6: Q-Q plot of the residuals for model 3

Compared to Model 2, the reduced model did not have a significant effect on the plots. The reduced $\log$ transformation model meets the required assumptions. We have also fitted both square root and inverse transformations models and found that constant variance assumption have not met, so we have decided not to report in this paper.

\subsection{Full Beta Regression (Model 4)}

We divided the dependent variable (y) by $\mathrm{x} 3$, ie. $y^{*}=y / x_{3}$, which is the total population by county, to get a proportion for the beta model. To see whether $\mathrm{y}^{*}$ follow beta distribution or not, we have done the following analysis in $\mathrm{R}$. Using $\mathrm{R}$ we obtain the values of the parameters of Beta distribution as, $\alpha=6.725$ and $\beta=3674.04$. One sample KolmogorovSmirnov test is obtained as ks=0.0693 with $\mathrm{P}$ value $=0.882$, which indicates that the transformed data follow a beta distribution with alpha $=6.72$ and btea $=3674.035$. For more on Beta regression modelling, see Ferrari and Cribari-Neto (2004) and Cribari-Neto and Zeileis (2010) among others. The mean of the response variable $\mathrm{y}^{*}$ can be written as,

$$
\begin{aligned}
& \mathrm{E}\left(\mathrm{y}^{*}\right)=\beta_{0}+\beta_{1} \mathrm{x}_{1}+\beta_{2} \mathrm{x}_{2}+\beta_{3} \mathrm{x}_{3}+\beta_{4} \mathrm{X}_{4}+\beta_{5} \mathrm{x}_{5} \\
& +\beta_{6} \mathrm{x}_{6}+\beta_{7} \mathrm{X}_{7}+\beta_{8} \mathrm{x}_{8}+\beta_{9} \mathrm{x}_{9}+\beta_{10} \mathrm{x}_{10}+\beta_{11} \mathrm{x}_{11}+\beta_{12} \mathrm{x}_{12} \\
& +\beta_{13} \mathrm{x}_{13}
\end{aligned}
$$




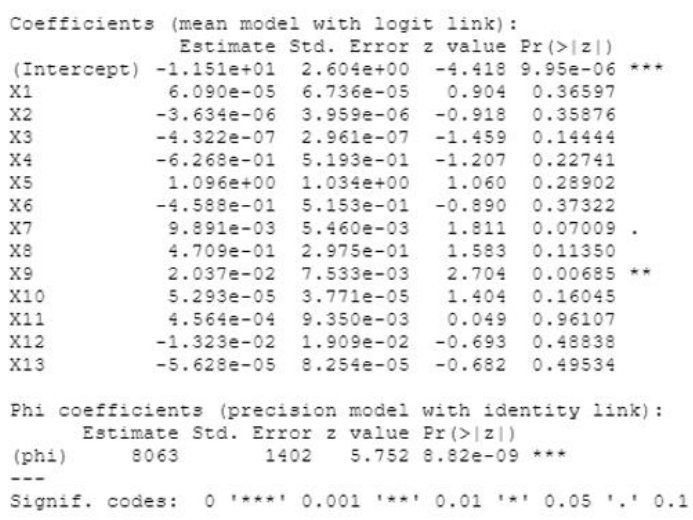

The fitted full Beta regression model (Model 4) is $\hat{y}^{*}=-11.51+0.00006090 \times 1-0.000003634 \times 2-$ $0.0000004322 \times 3-0.6268 \times 4+1.096 \times 5-$ $0.04588 \times 6+0.009891 \times 7+0.4709 \times 8+0.02037 \times 9+$ $0.00005293 \times 10+0.0004564 \times 11-0.01323 \times 12-$ $0.00005628 \times 13$

The observed vs fitted plot of the full model is presented in Figure 7, which indicates that the Beta regression model fit the data well.

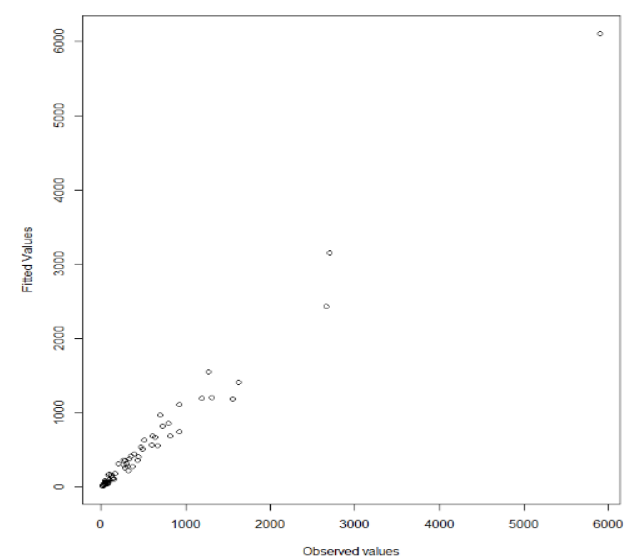

Fig. 7: Observed vs fitted plot for model 4

\subsection{Reduced Beta Model (Model 5)}

$\mathrm{E}\left(\mathrm{y}^{*}\right)=\beta_{0}+\beta_{3} \mathrm{X}_{3}+\beta_{4} \mathrm{X}_{4}+\beta_{5} \mathrm{X}_{5}+\beta_{7} \mathrm{X}_{7}+\beta_{8} \mathrm{X}_{8}+\beta_{9} \mathrm{X}_{9}$

\footnotetext{
Coefficients (mean model with logit link): Estimate Std. Error $z$ value $\operatorname{Pr}(>|z|)$

The reduced fitted Beta regression model (Model 5) is

$\hat{y}^{*}=-11.83+0.0001073 \times 1-0.0000003602 \times 3-$ $0.1669 \times 4+0.1713 \times 5+0.007902 \times 7+0.4659 \times 8+$ $0.02534 \times 9$

The fitted vs observed plot is presented in Figure 8, which indicates that the model fit the data well.

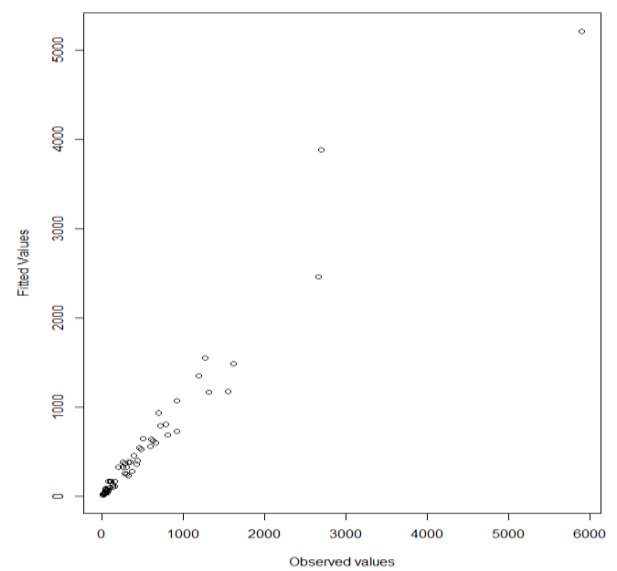

Fig. 8: Observed vs fitted plot for model 5

\subsection{Full Ridge Regression Model (Model 6)}

In linear regression model (3.1), we assumed that the regressors in the model are independent. However, the following correlation matrix (Table 2) exhibit linear relationship among the regressors, which causes the multicollinearity problem. About the correlation analysis, readers are referred to Chutiman et al. (2019) among others. The parameters in the linear regression model (3.1) are usually estimated using the ordinary least squares (OLS) estimator. In the presence of multicollinearity, least square estimators possess high standard error, and occasionally, the estimated regression coefficients exhibit wrong signs. As such, it becomes impossible to make valid statistical inference about the regression parameters (Kibria 2003). Hoerl and Kennard (1970) developed the ridge regression estimator as a notable alternative to the OLS estimator in the linear regression model (LRM).

Table 2. Correlation Matrix

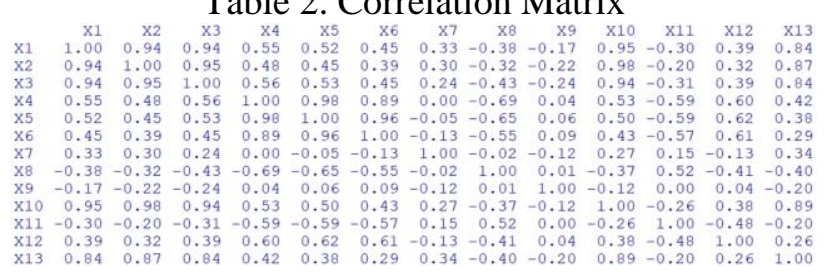


Table 3. VIF for the predictors

\begin{tabular}{|l|l|}
\hline Variable & VIF \\
\hline X1 & 17.2 \\
X2 & 58.5 \\
X3 & 16.0 \\
X4 & 3044.9 \\
X5 & 7804.2 \\
X6 & 1287.8 \\
X7 & 1.6 \\
X8 & 2.3 \\
X9 & 1.7 \\
X10 & 80.2 \\
X11 & 1.9 \\
X12 & 1.9 \\
X13 & 6.3 \\
\hline
\end{tabular}

From Table 3, we can see that 7 out of the 13 regression coefficients have a $V I F j>10$, which certainly exhibit the existing of multicollinearity in the data. There are many ways to estimate ridge regression parameter k exist in literature (see Kibria 2003, Kibria and Banik 2012). However, for our convenient, we consider the ridge trace to estimate the parameter $\mathrm{k}$. The Ridge Trace (Hoerl and Kennard, 1970) plot in (Figure 9), shows $\mathrm{k}=0.1$ is the biased estimate which stabilizes the regression coefficients the best.

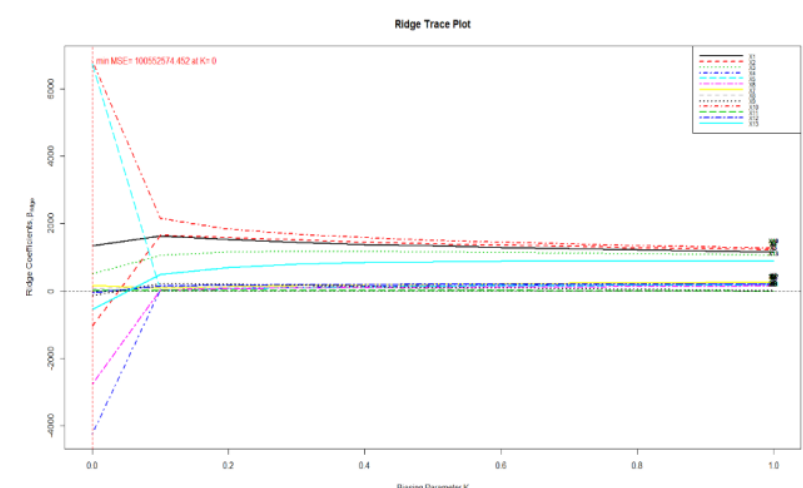

Fig. 9: Ridge trace plot for the coefficients of the predictors

By adjusting to $\mathrm{k}=0.1$ the VIF for the Full Model is corrected and none of the VIF values are above 10 . The results from (Model 6) show that $\mathrm{R}$ square is 0.9375, which represents about $94 \%$ of total variation of deaths due to COVID-19 could be explained by the 13 variables. The p-value in (Model 6) is approximately 0. From the lmridge calculation the ridge parameter $\mathrm{k}=0.1$ improves the model the most. We can see from the following output that all of the coefficients have positive signs, while some of the coefficients in models (3.1) to (3.5) have wrong negative signs.

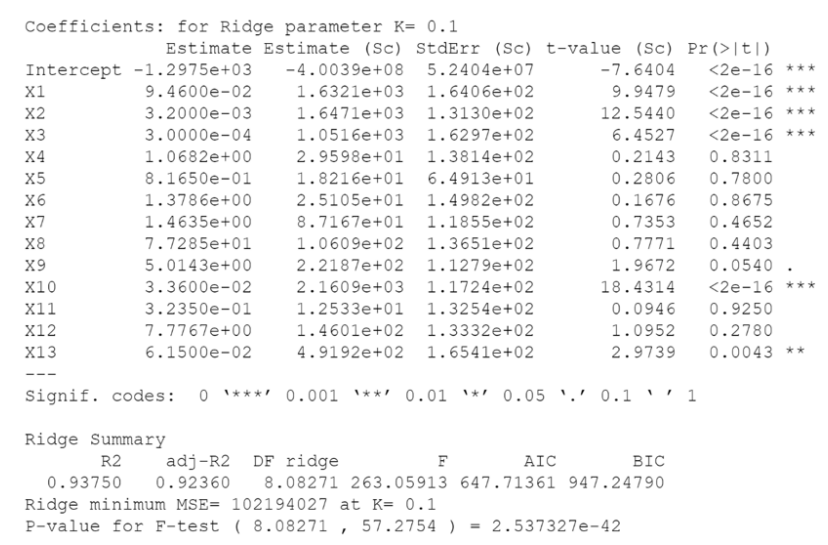

The fitted Full Ridge Regression Model (Model 6) is

$\hat{y}=-$

$1297.5+0.0946 \times 1+0.0032 \times 2+0.0003 \times 3+1.0682$

$\mathrm{x} 4+0.8165 \times 5+1.3786 \times 6$

$+1.4635 \times 7+77.285 \times 8+5.0143 \times 9+0.0336 \times 10+0$. $3235 \times 11+7.7767 \times 12+0.0615 \times 13$

\section{Cross Validation}

Since we have several well fitted models for the same data, a cross validation is needed to find the possible best model. To decide which model we will give the best fit, we will use five different randomly selected variations of the 67 observation. We will fit the models with $80 \%$ (50 counties) of each variation and then predict the other 20\% (17 counties) to evaluate the adequacy of the model. Since the following models, namely, the Log Transformation (Model 2), Reduced Log Transformation (Model 3), Beta Transformation (Model 4), Reduced Beta Transformation (Model 5), Full Ridge Model (Model 6) met the model assumption, we consider them only for the cross validation. To evaluate the models, following Bai et al. (2019), we will calculate the following metrices, namely, Mean Absolute Error (MAE), Root Mean Square Error (RMSE), Range-normalized RMSE (NRMSE), and Mean Absolute Percentage Error (MAPE) of each variation and average them. The estimated value of the metrices is presented in Table 4.1. From Table 4.1, we can see that the MAE, RMSE, and NRMSE are the lowest for the full ridge regression model. The model with the best MAPE value is the reduced beta transformation. Therefore, we consider the full ridge regression model as the possible best model. 
The final fitted model is

$\hat{y}=-1297.5+0.0946 \times 1+0.0032 \times 2$

$+0.0003 \times 3+1.0682 \times 4+0.8165 \times 5+1.3786 \times 6$

$+1.4635 \times 7+77.285 \times 8+5.0143 \times 9+0.0336 \times 10+0$.

$3235 \times 11+7.7767 \times 12+0.0615 \times 13$

Table 4. Evaluation metrics for different models

\begin{tabular}{|l|l|l|l|l|}
\hline Model & MAE & RMSE & NRMSE & MAPE \\
\hline Log Transformation & 289.8 & 585.5 & 0.3469 & 1.07 \\
\hline $\begin{array}{l}\text { Reduced Log } \\
\text { Trinsformation }\end{array}$ & 234.47 & 413.63 & 0.2411 & 0.989 \\
\hline Beta regression & 118.62 & 247.995 & 0.1169 & 0.305 \\
\hline $\begin{array}{l}\text { Reduced Beta } \\
\text { regression }\end{array}$ & 112.997 & 228.31 & 0.1105 & 0.304 \\
\hline Full Ridge & 67.0491 & 114.0379 & 0.05417 & 0.3662 \\
\hline
\end{tabular}

As an application of the final fitted model (4.1), we predicted the total number of deaths due to COVID19 for the first five Florida counties and provided them in Table 5.

Table 5. Observed and predicted values for some selected counties

\begin{tabular}{|l|l|l|l|l|l|l|}
\hline County & Observed & LT & RLT & BR & RBR & FR \\
\hline Alachua & 259 & 289.2 & 319.6 & 299.5 & 322.6 & 264.8 \\
\hline Baker & 61 & 70.6 & 68.2 & 66.2 & 66.5 & 41.9 \\
\hline Bay & 375 & 221.8 & 231.6 & 271.3 & 277.8 & 345.2 \\
\hline Bradford & 55 & 47.5 & 60.7 & 58.5 & 64.7 & 82.6 \\
\hline Bevard & 814 & 559.8 & 722.5 & 690.7 & 687.6 & 757.0 \\
\hline
\end{tabular}

From Table 5, we can see that the full ridge model predicted the observed number of deaths better than the rest of the fitted models.

\section{Conclusion}

The paper considers some regression models to fit the number of deaths due to COVID-19 for Florida counties. Thirteen (13) regressors, namely, hospitalizations, total cases, population, minimum temperature, average temperature, max temperature, precipitation, mobility index, median age, adults age 65 or more, PM2.5 average, ozone average, and positive non-residents were used to fit the models. Since VIFs indicated the problem of multicollinearity, we used ridge regression method to address the multicollinearity problem. Cross validation results indicated that the full ridge regression model performed the best among five fitted models. Of the 13 regressors, the following six variables: hospitalizations per county (x1), total cases per county (x2), population per county (x3), median age per county (x9), positive adults 65 or older per county (x10), and positive non-residents per county $(\mathrm{x} 13)$ were significant for the final model.
For our convenient, we have estimated the ridge parameter $\mathrm{k}$ from ridge trace (Hoerl and Kennard 1970). However, since there are many methods exist to estimate the ridge parameter $\mathrm{k}$, as a future research, this data can be applied for estimation of $\mathrm{k}$ for different models. Besides ridge regression approach, Liu (1993) and Kibria-Lukman (Kibria and Lukman 2020) estimators and Stein type (1956) estimator among other methods can be used to solve the multicollinearity problem. We strongly believe that the data of this paper will be an excellent source for illustrating multicollinear linear regression models.

\section{Acknowledgements:}

The authors are thankful to the editor and reviewers for their valuable comments/suggestions, which certainly improved the quality and presentation of the article.

\section{References:}

[1] Abdullah, W. G., Rianse, U., Iswandi, R. M., Taridala, S. A. A., Yunus, L, Fausayana, I., Dirgantoro, M. A. Rianese, I. S. and Batoa, H. (2016) Factors Affecting the Preferences of Agribusiness Actors of Aren Sugar toward Marketing Risk, WSEAS Transactions on Business and Economics. 13, 408-413.

[2] Amin, M., Akram, M.M. and Kibria, B. M. G. (2021). A new adjusted Liu estimator for the Poisson regression model. Concurrency Computer Pract Exper. DOI: 10.1002/cpe.6340

[3] Bai, X. and Zhang, F. and Lee, I. (2010). Predicting the citations of scholarly paper. Journal of Informetrics, 13, 407-418.

[4] Climate at a Glance. National Oceanic and Atmospheric Administration (NOAA).

[5] https://www.ncdc .noaa.gov /cag/county/mapping/8/pcp/202101/18/value

[6] Chutiman, N., Busabarodhin, P., Senapeng,T. P. and Chitangpradit, M. (2019). Correlation analysis between extreme weather event and agricultural damage value in Northeast of Thailand. WSEAS Transections on Environmental and development. 15, 257-260. 
[7] Chen, D-G and Chen, J. K. (2021). Statistical regression analysis modelling with $\mathrm{R}$. Springer, Cham, ISBN: 978-3-030-67585-1.

[8] Cohen, Y. and Cohen, J. Y. (2008). Statistics and Data with R: An applied approach through examples, Wiley, New York.

[9] Covid-19 Data Tracker. Center for Disease Control and Prevention. https://www.cdc.gov/ coronavirus/2019-ncov/index.html

[10] Cribari-Neto F, Zeileis A (2010). Beta Regression in R. Journal of Statistical Software, 34(2), 1-24. URL http://www.jstatsoft.org/v34/i02/.

[11] Draper, N. R. and Smith, H.. (1998). Applied Regression Analysis, Third Edition. Wiley, New York 1998.

[12] Ferrari, S. I. O and Cribari-Neto, F. (2004). Beta regression for modelling rates and proportions. Journal of Applied Statistics. 31(7), 799-815.

[13] Florida coronavirus cases and deaths. https://usafacts.org/visualizations/coronavirus -covid-19- spread-map/state/florida

[14] Florida's COVID-19 Data and Surveillance Dashboard. Site Map. https://experience.arcgis.com/ experience/96dd742462124fa0b38ddedb9b25 e429

[15] Gibbons, D.G. (1981). A simulation study of some ridge estimators. Journal of the American Statistical Association, vol. 76, pp.131-139.

[16] Gruber, M. H. J. (2010). Regression estimators, Second Edition, University Press, Baltimore.

[17] Ghosal, S., Sengupta, S., Majumder, M. and Sinha, B. (2020). Linear regression analysis to predict the number of deaths in India due to SARS-CoV-2 at 6 weeks from 0 (100 casesMarcg 14th 2020). Diabetes \&amp; Metabolic Syndrome: Clinical Research \&amp; Reviews, 12, 311-315.

[18] Guzman, C. I and Kibria, B. M. G. (2019). Developing Multiple Linear Regression Models for the Number of Citations: A Case Study of Florida International University Professors. International Journal of Statistics and Reliability Engineering, 6(2), 75-81.

[19] Hoerl AE, Kennard RW (1970) Ridge regression: Biased estimation for nonorthogonal problems. Technometrics 12(1):55-67.
[20] Kibria, B.M.G. (2003). Performance of some new ridge regression estimators. Communication in Statistics-Simulation and Computation, vol.32, pp.419-435.

[21] Kibria, B. M. G. and S. Banik (2016). Some Ridge Regression Estimators and Their Performances. Journal of Modern Applied Statistical Methods. 15 (1), 206-238.

[22] Kibria, B. M. G. and Lukman, A. F. (2020). A New Ridge-Type Estimator for the Linear Regression Model: Simulations and Applications. Scientifica, Volume 2020, Article ID 9758378, 16 pages.

[23] Liu, K.J., 1993. A new class of biased estimate in linear regression. Commun. Statist. Theory Meth. 22 (2), 393-402.

[24] Lukman, A. F. K. Ayinde, S. Binuomote, and O. A. Clement, (20191), "Modified ridge-type estimator to combat multicollinearity: application to chemical data," Journal of Chemometrics, vol. 33, no. 5, p. e3125, 2019. [14]

[25] Lukman, A. F., K. Ayinde, S. K. Sek, and E. Adewuyi, (2019b), "A modified new twoparameter estimator in a linear regression model," Modelling and Simulation in Engineering, vol. 2019, Article ID 6342702, 10 pages, 2019.

[26] Montgomery, D. C., Peck, E. A. and Vining, G. G. (2013). Introduction to Linear Regression Analysis. Wiley-Blackwell, 2013.

[27] Muniz, G. and Kibria, B.M.G. (2009). On some ridge regression estimators: An empirical comparison. Communication in Statistics-Simulation and Computation, vol.38, pp.621-630.

[28] Muniz, G., Kibria, B.M.G. Mansson, K and Shukur, G. (2012). On developing ridge regression parameters: A graphical investigation. SORT, vol.36, pp.115-138.

[29] Ogundokun, R. O., Lukman, A. F., Kibria, B. M. G., Awotunde, J. B. and Aladetian, B. B. (2020). Predictive modeling of COVID-10 confirmed cases in Nigeria. Infectious Disease Modelling. 5, 543-548.

[30] Qasim, M., Mansson, K. and Kibria, B. M. G. (2021). On some beta ridge regression estimators: methods, simulation and application. Journal of Statistical Computation and Simulation. 91(9), 1699-1712. 
[31] Qin, L., Sun, Q., Wang, Y., Wu, K-F, Chen M. Shia, B-C, and Wu, S-Y (2020). Predicting of number of cases of 2019 Novel Coronovirus (COVID-19) using social media search index. International Journal of Environmental Research and Public Health. 17, 2365.

[32] Siegrist, M and Kibria, B. M. G. (2020). Predicting Total Death using COVID-19 Data: Regression Model Approach. International Journal of Industrial and Operations Research. 2020, 3:008

[33] Saleh, A. K. Md. E., Arashi, M., and Kibria, B. M. G. (2019). Theory of Ridge Regression Estimation with Applications. Wiley, New York.

[34] Suhail, M, Chand, S and Kibria, B. M. G. (2020). Quantile-based robust ridge $\mathrm{m}$ estimator for linear regression model in presence of multicollinearity and outliers. Communications in Statistics-Simulation and Computation. 50 (11), 3194-3206.

[35] Stein, C. (1956), "Inadmissibility of the usual estimator for the mean of a multivariate distribution", Proc. Third Berkeley Symp. Math. Statist. Prob., vol. 1, pp. 197206, MR 0084922, Zbl 0073.35602
Contribution of Individual Authors to the Creation of a Scientific Article (Ghostwriting Policy)

B M Golam Kibria designed the statistical methods. Manuel Urbistondo collected and edited the data and analyzed them. Both authors discussed the results and contributed to the final manuscript. B M Goalm Kibria revised the whole paper and typed in the journal format.

\section{Creative Commons Attribution License 4.0} (Attribution 4.0 International, CC BY 4.0)

This article is published under the terms of the Creative Commons Attribution License 4.0 https://creativecommons.org/licenses/by/4.0/deed.en _US 
Appendix: Covid data for the state of Florida, USA

\begin{tabular}{|c|c|c|c|c|c|c|c|c|c|c|c|c|c|c|}
\hline Counties & $\mathrm{Y}$ & $\mathrm{X} 1$ & $\mathrm{x} 2$ & X3 & $\mathrm{X} 4$ & $\mathrm{x} 5$ & $\mathrm{x} 6$ & $\mathrm{X7}$ & $\mathrm{x} 8$ & X9 & X10 & $\mathrm{X} 11$ & $\mathrm{X} 12$ & $\mathrm{X} 13$ \\
\hline Alachua County & 259 & 1132 & 23559 & 269043 & 60.6 & 71.6 & 82.7 & 53.89 & 3.9 & 27 & $7 \quad 2407$ & 16.34 & 58.5 & 279 \\
\hline Baker County & 61 & 177 & 3371 & 29210 & 58.1 & 69.6 & 81.1 & 56.06 & 4.3 & 42 & 488 & 23.66 & 54.5 & 15 \\
\hline Bay County & 375 & 800 & 19462 & 174705 & 61.2 & 70.7 & 80.2 & 64.84 & 4 & 43 & 3136 & 28.04 & 57.3 & 765 \\
\hline Bradford County & 55 & 146 & 2925 & 28201 & 59.8 & 70.9 & 82.1 & 55.62 & 4.3 & 45 & 548 & 16 & 58 & 13 \\
\hline Brevard County & 814 & 2176 & 37563 & 601942 & 66.4 & 74.4 & 82.4 & 53.35 & 4 & 43 & 6835 & 17.06 & 57.8 & 674 \\
\hline Broward County & 2699 & 9502 & 217060 & 1952778 & 68.4 & 77.4 & 86.3 & 78.94 & 4 & 38 & 23192 & 19.26 & 59.5 & 2604 \\
\hline Calhoun County & 42 & 57 & 1662 & 14105 & 59.3 & 70.1 & 80.8 & 64.57 & 4.3 & 45 & 392 & 28 & 57 & 3 \\
\hline Charlotte County & 392 & 861 & 11714 & 188910 & 65.7 & 75.8 & 85.9 & 56.9 & 4 & 57 & 4090 & 19 & 61 & 203 \\
\hline Citrus County & 432 & 675 & 10389 & 149657 & 63 & 73.5 & 83.9 & 49.54 & 4.1 & 55 & 3515 & 23.45 & 60 & 91 \\
\hline Clay County & 329 & 901 & 17447 & 219252 & 61.8 & 72.1 & 82.4 & 54.32 & 4.1 & 43 & 2859 & 16.5 & 58 & 48 \\
\hline Collier County & 505 & 1611 & 32836 & 384902 & 66.7 & 76.5 & 86.4 & 56.87 & 4 & 44 & 6534 & 21.27 & 58.3 & 1254 \\
\hline Columbia County & 163 & 456 & 7877 & 71686 & 57.7 & 69.3 & 80.8 & 55.84 & 4.2 & 43 & 1389 & 32.23 & 50.4 & 37 \\
\hline DeSoto County & 86 & 288 & 4101 & 38001 & 64.3 & 74.9 & 85.6 & 55.24 & 4 & 42 & 643 & 21 & 58 & 26 \\
\hline Dixie County & 22 & 112 & 1556 & 16826 & 60.6 & 71 & 81.4 & 53.4 & 4.3 & 44 & 317 & 17 & 56.3 & 3 \\
\hline Duval County & 1311 & 2046 & 92993 & 957755 & 61.9 & 71.6 & 81.3 & 54.82 & 4.1 & 38 & 11952 & 25.31 & 57 & 1530 \\
\hline Escambia County & 669 & 2103 & 34950 & 318316 & 59 & 69.1 & 79.1 & 69.05 & 4 & 41 & 6513 & 20.01 & 55.7 & 3636 \\
\hline Flagler County & 99 & 365 & 6751 & 115081 & 64 & 73.2 & 82.4 & 51.69 & 4 & 46 & 1364 & 17 & 54 & 94 \\
\hline Franklin County & 17 & 29 & 1296 & 12125 & 61.1 & 70.7 & 80.3 & 58.31 & 4.2 & 44 & 246 & 24.6 & 55.3 & 33 \\
\hline Gadsden County & 90 & 417 & 5544 & 45660 & 58.7 & 69.4 & 80.1 & 58.46 & 4.4 & 41 & 710 & 28.43 & 56 & 16 \\
\hline Gilchrist County & 38 & 75 & 1495 & 18582 & 59.6 & 70.9 & 82.1 & 52.47 & 4.4 & 40 & 271 & 19.76 & 57.8 & 4 \\
\hline Glades County & 19 & 69 & 926 & 13811 & 65.1 & 75.4 & 85.6 & 53.56 & 4.3 & 38 & 119 & 16 & 58 & 4 \\
\hline Gulf County & 42 & 96 & 1920 & 13639 & 61 & 70.8 & 80.5 & 61 & 4.2 & 50 & 436 & 27 & 56 & 23 \\
\hline Hamilton County & 23 & 80 & 1593 & 14428 & 57.5 & 68.7 & 79.8 & 55.25 & 4.4 & 41 & 232 & 27.06 & 53 & 19 \\
\hline Hardee County & 39 & 218 & 2915 & 26937 & 63.9 & 74.7 & 85.4 & 51.65 & 4.2 & 37 & 388 & 20.39 & 59.68 & 14 \\
\hline Hendry County & 77 & 335 & 4479 & 42022 & 65.7 & 75.9 & 86.1 & 49.2 & 4.2 & 38 & 576 & 25 & 59 & 18 \\
\hline Hernando County & 443 & 977 & 12543 & 193920 & 63.8 & 74.1 & 84.3 & 49.12 & 4.1 & 50 & 3265 & 24.28 & 58.73 & 96 \\
\hline Highlands County & 323 & 610 & 7732 & 106221 & 64.6 & 74.9 & 85.2 & 54.4 & 4 & 52 & 2433 & 18.5 & 58.3 & 88 \\
\hline Hillsborough County & 1619 & 2971 & 123169 & 1471968 & 65.6 & 75.1 & 84.6 & 53.32 & 4 & 37 & 14565 & 21.32 & 63 & 1059 \\
\hline Holmes County & 47 & 89 & 2216 & 19617 & 57.5 & 68.9 & 80.3 & 71.82 & 4.4 & 44 & 414 & 28.12 & 53.9 & 32 \\
\hline Indian River County & 282 & 813 & 11790 & 159923 & 65.6 & 74.6 & 83.6 & 64.54 & 4 & 45 & 2753 & 17 & 58 & 104 \\
\hline Jackson County & 155 & 352 & 6068 & 46414 & 58.6 & 69.4 & 80.2 & 65.94 & 4.3 & 44 & 1155 & 28 & 54 & 65 \\
\hline Jefferson County & 25 & 76 & 1432 & 14246 & 59.6 & 69.9 & 80.2 & 54.51 & 4.4 & 47 & 279 & 32 & 56 & 22 \\
\hline Lafayette County & 25 & 48 & 1606 & 8422 & 59 & 70.1 & 81.2 & 54.14 & 4.4 & 39 & 186 & 18.38 & 57.05 & 0 \\
\hline Lake County & 610 & 1386 & 26924 & 367118 & 64 & 74.2 & 84.3 & 48.46 & 4.1 & 45 & 6098 & 21 & 60.1 & 460 \\
\hline Lee County & 923 & 2143 & 63334 & 770577 & 66.9 & 76.3 & 85.8 & 55.91 & 4 & 43 & 12389 & 18.53 & 61.2 & 2180 \\
\hline Leon County & 306 & 657 & 30406 & 293582 & 59.2 & 69.8 & 80.4 & 56.94 & 3.9 & 28 & 2499 & 32.44 & 55.5 & 895 \\
\hline Levy County & 44 & 207 & 3139 & 41503 & 62 & 72.4 & 82.8 & 49.22 & 4.3 & 43 & 578 & 20.26 & 59.53 & 8 \\
\hline Liberty County & 16 & 22 & 1056 & 8354 & 59.3 & 70.1 & 80.9 & 61.36 & 4.4 & 39 & 116 & 27.5 & 57.5 & 1 \\
\hline Madison County & 44 & 88 & 2034 & 18493 & 58.8 & 69.5 & 80.1 & 53.47 & 4.4 & 43 & 371 & 29.53 & 55 & 26 \\
\hline Manatee County & 635 & 1434 & 35161 & 403253 & 64.8 & 74.7 & 84.6 & 54.51 & 4 & 42 & 6410 & 18.59 & 54.7 & 820 \\
\hline Marion County & 926 & 1971 & 29225 & 365579 & 62.3 & 72.8 & 83.3 & 51.79 & 4.1 & 45 & 6420 & 20.48 & 60 & 147 \\
\hline Martin County & 309 & 745 & 11465 & 161000 & 68 & 76.7 & 85.3 & 73.33 & 3.9 & 45 & 2509 & 19.47 & 56.6 & 214 \\
\hline Miami-Dade County & 5813 & 12624 & 449891 & 2716940 & 69.5 & 78 & 86.6 & 70.64 & 4 & 40 & 55621 & 20.49 & 60.4 & 5773 \\
\hline Monroe County & 49 & 253 & 6504 & 74228 & 70.4 & 78.5 & 86.5 & 62.81 & 3.8 & 42 & 899 & 21 & 59 & 373 \\
\hline Nassau County & 120 & 296 & 7996 & 88625 & 60.2 & 70.6 & 81 & 54.13 & 4.2 & 45 & 1432 & 26.21 & 55.75 & 436 \\
\hline Okaloosa County & 353 & 692 & 19799 & 210738 & 58 & 68.8 & 79.5 & 68.63 & 4 & 40 & 3019 & 21 & 55.8 & 211 \\
\hline Okeechobee County & 86 & 387 & 3768 & 42168 & 65.4 & 75.1 & 84.8 & 61.75 & 4 & 41 & 655 & 19 & 58 & 52 \\
\hline Orange County & 1190 & 2606 & 125108 & 1393452 & 65.1 & 74.7 & 84.3 & 50.77 & 4 & 36 & 11750 & 17.55 & 54.2 & 1898 \\
\hline Osceola County & 487 & 1364 & 40024 & 375751 & 65 & 74.8 & 84.5 & 52.06 & 4.1 & 38 & 4363 & 20.76 & 60.1 & 704 \\
\hline Palm Beach County & 2661 & 6427 & 132961 & 1496770 & 68 & 76.9 & 85.9 & 71.65 & 4 & 40 & 19434 & 15.28 & 57.6 & 2417 \\
\hline Pasco County & 697 & 2420 & 36787 & 553947 & 64.4 & 74.4 & 84.4 & 52.01 & 4 & 44 & 7112 & 16 & 57.5 & 322 \\
\hline Pinellas County & 1557 & 4581 & 73080 & 974996 & 67.6 & 75.5 & 83.3 & 51.42 & 3.9 & 43 & 13443 & 16.14 & 62.1 & 1813 \\
\hline Polk County & 1267 & 4820 & 61747 & 724777 & 64.6 & 74.9 & 85.1 & 54.14 & 4.1 & 41 & 10182 & 19.13 & 60.5 & 453 \\
\hline Putnam County & 135 & 528 & 6060 & 74521 & 63.2 & 73 & 82.7 & 52.01 & 4.2 & 42 & 1128 & 18.17 & 57 & 21 \\
\hline St. Johns County & 203 & 742 & 21294 & 264672 & 64.1 & 72.9 & 81.8 & 52.48 & 4.1 & 41 & 3008 & 22.5 & 55.3 & 298 \\
\hline St. Lucie County & 594 & 1657 & 24197 & 328297 & 66.6 & 75.5 & 84.5 & 72.69 & 4.1 & 43 & 4388 & 19 & 57 & 176 \\
\hline Santa Rosa County & 278 & 858 & 17805 & 184313 & 58.1 & 68.4 & 78.7 & 69.28 & 4.2 & 42 & 2706 & 20.64 & 58.6 & 231 \\
\hline Sarasota County & 791 & 1298 & 29679 & 433742 & 64.6 & 74.7 & 84.8 & 54.96 & 4 & 49 & 7716 & 20.5 & 57.7 & 1478 \\
\hline Seminole County & 468 & 1199 & 30410 & 471826 & 65 & 74.5 & 83.9 & 50.96 & 3.9 & 38 & 3797 & 16.97 & 58.9 & 236 \\
\hline Sumter County & 261 & 558 & 8852 & 132420 & 62.9 & 73.7 & 84.6 & 47.47 & 3.9 & 65 & 4394 & 19.3 & 58 & 103 \\
\hline Suwannee County & 135 & 311 & 5224 & 44417 & 58.2 & 69.5 & 80.7 & 54.76 & 4.3 & 44 & 957 & 26 & 54.73 & 28 \\
\hline Taylor County & 45 & 96 & 2695 & 21569 & 60.7 & 70.7 & 80.8 & 53.67 & 4 & 41 & 394 & 19 & 56 & 5 \\
\hline Union County & 71 & 82 & 1776 & 15237 & 58.4 & 70 & 81.6 & 55.98 & 4.4 & 45 & 282 & 24 & 54 & 1 \\
\hline Volusia County & 726 & 1980 & 38819 & 553284 & 64.4 & 73.7 & 83 & 52.33 & 4 & 44 & 7382 & 16.87 & 57.5 & 689 \\
\hline Wakulla County & 55 & 157 & 3256 & 33739 & 60.2 & 70.4 & 80.6 & 58.09 & 4.4 & 43 & 504 & 32.86 & 54.4 & 12 \\
\hline Walton County & 83 & 290 & 7360 & 74071 & 58.2 & 69.2 & 80.1 & 69.52 & 4.2 & 42 & 1139 & 28 & 57 & 788 \\
\hline Washington County & 50 & 135 & 2678 & 25473 & 58.7 & 69.6 & 80.5 & 68.2 & 4.4 & 44 & 461 & 29.4 & 56.5 & 20 \\
\hline
\end{tabular}

